\title{
Modulation of oxidative stress by $\beta$-carotene in chicken embryo fibroblasts
}

\author{
BY SUSAN M. LAWLOR AND NORA M. O'BRIEN \\ Department of Nutrition, National Food Biotechnology Centre, University College, Cork, Ireland
}

(Received 21 July 1994 - Revised 24 October 1994 - Accepted 28 October 1994)

\begin{abstract}
The ability of $\beta$-carotene to protect against oxidative stress in vitro was assessed. Primary cultures of chicken embryo fibroblasts (CEF) were oxidatively stressed by exposure to paraquat (PQ). Activities of the antioxidant enzymes superoxide dismutase (SOD; EC 1.15.1.1), catalase (CAT; EC 1.11.1.6) and glutathione peroxidase (GSH-Px; EC 1.11.1.9) were measured as indices of oxidative stress. CEF incubated with 0.25 mM-PQ for $18 \mathrm{~h}$ exhibited increased SOD and CAT activities and decreased GSH$P x$ activity compared with the control $(P<0.001)$. Incorporation of added $\beta$-carotene $(0 \cdot 1 \mu \mathrm{M})$ into 0.25 mM-PQ-treated CEF returned SOD activity to that seen in non-PQ-treated cells. $\beta$-Carotene $(0.1 \mu \mathrm{M})$ reduced the $\mathrm{CAT}$ activity from that seen in PQ-treated cells and returned the GSH-Px activity to its control value thus protecting the cells against $P Q$-induced oxidative stress. However, at higher concentrations of $\beta$-carotene $(10 \mu \mathrm{M})$, SOD and CAT activities increased significantly $(P<0.001)$ relative to non-PQ-treated cells and GSH-Px activity decreased relative to its control value. Similar trends were observed when CEF grown in $\beta$-carotene-enriched media $(0.1-10 \mu \mathrm{M})$ were oxidatively stressed by exposure to $0.25 \mathrm{mM}-\mathrm{PQ}$ for $18 \mathrm{~h}$.
\end{abstract}

$\beta$-Carotene: Chicken embryo fibroblasts: Oxidative stress: Antioxidant enzymes

Normal cellular aerobic metabolism leads to the continuous generation of highly reactive $O$ species, including free radicals, which are capable of damaging cell macromolecules. Toxicity by $O$ radicals has been linked to the aetiology of a number of diseases such as cancer, ageing, radiation damage and inflammation (Di Mascio et al. 1991). As a result, important biological defence systems have evolved in humans to limit inappropriate exposure to reactive $O$ species.

Free radicals are chemical species with one or more unpaired electrons, such as the superoxide anion $\left(\mathrm{O}_{2}^{-}\right)$, hydroxyl radical ( $\left.\mathrm{HO}^{\circ}\right)$ and peroxyl radical ( $\mathrm{ROO}^{\circ}$ ). Highly reactive molecules which cause damage through free-radical generation include singlet $\mathrm{O}$ and $\mathrm{H}_{2} \mathrm{O}_{2}$. Under normal physiological conditions the organism can prevent free-radical damage by protective mechanisms which involve superoxide dismutase (SOD; $E C$ 1.15.1.1), catalase (CAT; EC 1.11.1.6) and glutathione peroxidase (GSH-Px; $E C$ 1.11.1.9). A further type of protection is afforded by nutritional antioxidants such as vitamin $\mathrm{E}$ (tocopherol) and the carotenoids.

The need for protection against free radicals is increased under certain conditions. Dietary factors, for example, have been shown to have the potential to modify oxidative stress. High-fat energy-rich diets, such as those commonly consumed in Western societies, may increase oxidative stress, decrease the capacity to respond to toxic insult and give rise to increased incidence of certain cancers (National Academy of Sciences, 1989). It has been shown in rats that diets containing as little as $100 \mathrm{~g}$ polyunsaturated fat $/ \mathrm{kg}$ increase significantly the extent to which DNA-binding metabolites of benzo[a]pyrene are produced 
(Kwei \& Bjeldanes, 1990), and that human diets rich in highly unsaturated lipid lead to increased peroxidation of plasma lipoproteins in both smokers and non-smokers (Harats et al. 1991).

Several lines of evidence suggest that important relationships exist between carotenoids and cancer (Mathews-Roth, 1985; Krinsky, 1989; Ziegler, 1991). It has been suggested that carotenoids may act as anticarcinogenic agents by an antioxidant mechanism independent of their conversion to vitamin A (Peto et al. 1981). However, few experimental studies have been reported on the antioxidant properties of carotenoids in in vitro whole-cell systems. Most studies have focused on the antioxidant properties of $\beta$-carotene and research has been largely conducted in liposomes (Krinsky \& Deneke, 1982), lipoproteins, (Jialal et al. 1991), and isolated membranes (Palozza et al. 1992). We have previously shown the efficacy of $\alpha$-tocopherol in inhibiting paraquat (PQ)-induced oxidative stress in a cellular model system using chicken embryo fibroblasts (CEF; Lawlor \& O'Brien, 1994). In the present study we examined the ability of $\beta$-carotene to protect against $P Q$-induced oxidative stress in CEF.

\section{MATERIALS AND METHODS \\ Materials}

The sources of chemicals and biochemical reagents were as indicated previously (Lawlor \& O'Brien, 1994). HAM's F10 medium (with glutamine and phenol red) and chicken serum were purchased from Flow Laboratories, Irvine, Scotland. All other culture media, including newborn calf serum and trypsin $(0 \cdot 25 \%)$, were purchased from GIBCO, Paisley, Scotland. $\beta$-Carotene (99-100\% pure) was obtained from F. Hoffmann-La Roche, Basel, Switzerland. Solvents were of HPLC grade and used without purification.

Chicken embryo fibroblasts. Chicken embryo fibroblasts (CEF) were prepared from 9-10d-old embryos (obtained from a local egg producer; Whittaker, Cork) by methods previously described (Lawlor \& O'Brien, 1994). Briefly, the cells were cultured in an atmosphere of air containing $\mathrm{CO}_{2}(50 \mathrm{ml} / \mathrm{l})$ at $37^{\circ}$ in HAM's F10 medium supplemented with penicillin/streptomycin $(50$ units $/ \mathrm{ml})$, tryptose phosphate broth $(3 \mathrm{~g} / 1), 7 \mathrm{~mm}$ $\mathrm{NaHCO}_{3}$ and $20 \mathrm{mM}-\mathrm{HEPES} \mathrm{pH} 7 \cdot 2$ (culture medium) to which $24 \mathrm{ml}$ chicken serum $/ 1$ and $100 \mathrm{ml}$ newborn calf serum $/ 1$ were added. After $4-5 \mathrm{~d}$ primary culture the cells were collected by trypsin (EC 3.4.21.4) treatment, resuspended in culture medium supplemented with newborn calf serum $(60 \mathrm{ml} / 1$; growth medium) and seeded in $100 \mathrm{~mm}$ diam. plastic Petri dishes $\left(2 \times 10^{6}\right.$ cells in $9 \mathrm{ml}$ per dish). After $4-5 \mathrm{~d}$ secondary culture the growth medium was removed and replaced by the same volume of incubation medium (126 mM-NaCl, $14 \mathrm{~mm}-\mathrm{NaHCO}_{3}, \quad 3.8 \mathrm{mM}-\mathrm{KCl}, \quad 0.9 \mathrm{~mm}-\mathrm{Na}_{2} \mathrm{HPO}_{4}, \quad 0.6 \mathrm{~mm}-\mathrm{KH}_{2} \mathrm{PO}_{4}$,

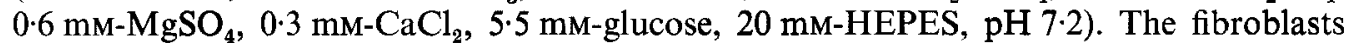
were then incubated in that medium with or without PQ and $\beta$-carotene for the indicated periods of time.

\section{Incubation of $C E F$ with test compounds}

Two experimental approaches were followed. With the first procedure the lipid-soluble antioxidant $\beta$-carotene was dissolved in absolute ethanol and subsequently diluted with incubation medium to the desired concentrations. The final concentration of absolute ethanol in cell cultures was $<1.0 \%$. PQ was dissolved in phosphate-buffered saline (PBS) and added at a final concentration of $0.25 \mathrm{~mm}$ to the incubation medium. In these experiments the incubation time with $\mathrm{PQ}$ and $\beta$-carotene was $18 \mathrm{~h}$ at $37^{\circ}$ in a humidified incubator with $50 \mathrm{ml} / 1 \mathrm{CO}_{2}$ in air. With the second procedure the cells were grown from primary culture in $\beta$-carotene-enriched media. Each flask or Petri dish received either $0 \cdot 1$, 
5 or $10 \mu \mathrm{M}-\beta$-carotene at each passage. Absolute ethanol was used to dissolve $\beta$-carotene and was added alone in the control group. Comparisons were made between the ethanol addition and no ethanol addition to the CEF. No significant difference in enzyme activity was determined on comparing the two groups of cells. The final concentration of absolute ethanol in the cell cultures was $<1.0 \%$. The cells were therefore subjected to a particular exogenous level of $\beta$-carotene from the time of initial seeding until the end of the experiment. Eighteen hours before the end of the experiment the growth medium was removed and replaced with incubation medium supplemented with $0.25 \mathrm{~mm}-\mathrm{PQ}$. Lactate dehydrogenase ( $\mathrm{LDH} ; E C$ 1.1.1.27) release was determined in all in vitro preparations as an index of cytotoxicity by the method of Vassault (1983). LDH release was expressed as a percentage of the total LDH released from cells treated with Triton $(100 \mathrm{~g} / \mathrm{l})$.

\section{Cell sonicates and enzyme activity measurement}

The incubation medium was rapidly aspirated to prepare the cell sonicates for enzymic analysis and $0.5 \mathrm{ml}$ of the appropriate buffer was added at $0^{\circ}$ to the cell layer. The cells were removed from the dishes by scraping and placed on ice. The CEF were disrupted by pulse sonication using an MSE Soniprep (Model 150) at $13 \mathrm{amps} / \mathrm{s}$. All sonications were performed for $20 \mathrm{~s}$ with cells at $4^{\circ}$. The sonicates were centrifuged for $10 \mathrm{~min}$ at $100000 \mathrm{~g}$ using a Beckman TL 100 mini-ultracentrifuge at $4^{\circ}$. CAT activity in cell sonicates was determined on the same day as harvesting using the method of Baudhuin et al. (1964). The remaining supernatant fractions were stored at $-20^{\circ}$ until SOD activity determined by the method of McCord \& Fridovich (1969), and GSH-Px activity by the method of Guenzler et al. (1974) were measured. Total protein was determined in each sonicate using the Biorad microassay (Bradford, 1976) using bovine serum albumin as the standard.

\section{Determination of $\beta$-carotene in $C E F$}

The incubation medium was rapidly aspirated to prepare the cell sonicates for measurement of $\beta$-carotene and $0.5 \mathrm{ml} 10 \mathrm{ml} / \mathrm{l}$ pyrogallol in absolute ethanol was added at $0^{\circ}$ to the cell layer. The cells were removed from the dishes by scraping and placed on ice. The CEF were disrupted by pulse sonication as described above. A $100 \mu 1$ portion of each homogenate was removed for protein analysis using the Biorad microassay (Bradford, 1976). Saponification and extraction of the cell sonicates was according to the method of Buttriss \& Diplock (1984) modified by dissolving the lipid residue in acetonitrile-methanol-water $(47: 47: 6$, by volume).

\section{HPLC analysis}

$\beta$-Carotene was quantified by HPLC using a Shimadzu LC-10AD pump (Shimadzu Europa GmbH, Duisburg, Germany), a Rheodyne 7125 syringe-loading injector (Rheodyne Inc., Cotati, CA, USA), with a $20 \mu 1$ loop, and a Machery-Nagel Nucleosil 5 C18 column (Machery-Nagel GmbH, Duren, Germany). A Guard-Pak filter unit (Waters Chromatography Division, Millipore (UK) Ltd., Watford, Herts.) was fitted to protect the column. The mobile phase was acetonitrile-methanol-water $(47: 47: 6$, by volume) with a modified flow rate of $2 \cdot 2 \mathrm{ml} / \mathrm{min}$ (Thurnham et al. 1988). This solvent mixture was degassed by sonication before use. The injected sample volume was usually $30-40 \mu 1$ and $\beta$-carotene was detected by measuring absorbance of the eluate at $450 \mathrm{~nm}$ using a Shimadzu SPD-10AV spectrophotometric detector. The retention time for $\beta$-carotene was $7.6 \mathrm{~min}$. A Shimadzu C-R5A chromatopac integrator was used to calculate the peak areas, which were quantified by reference to standard curves of peak areas derived from standard solutions 
of $\beta$-carotene. The $\beta$-carotene concentrations were then expressed relative to the total protein content of the homogenates.

\section{Statistical analysis}

All enzyme activities were expressed as units of enzyme activity/mg protein. Results are presented as mean values and standard errors of the means. Data were analysed by oneway analysis of variance. To follow up ANOVA, means were compared by Student's $t$ test (Snedecor, 1964). The level of statistical significance was taken as $P<0.05$.

\section{RESULTS}

\section{Effect of $P Q$ on SOD, CAT and GSH-Px activities}

As previously reported (Lawlor \& O'Brien, 1994), PQ does not affect the three antioxidant enzymes in a similar manner, i.e. it induces SOD and CAT and inhibits GSH-Px. SOD and CAT activities increased significantly $(P<0.001)$ relative to the control following exposure to $0.25 \mathrm{~mm}$-PQ for $18 \mathrm{~h}$. In contrast, GSH-Px activity decreased significantly $(P<0.001)$ on exposure to $0 \cdot 25$ mM-PQ (Figs. 1, 2 and 3).

\section{Antioxidant potential of $\beta$-carotene}

Having established an appropriate in vitro model system (Lawlor \& O'Brien, 1994) we tested the antioxidant potential of $\beta$-carotene using two different experimental approaches. First, CEF were incubated with $0.25 \mathrm{~mm}$-PQ and $\beta$-carotene $(0.05-10 \mu \mathrm{M})$ for $18 \mathrm{~h}$. The incorporation of $\beta$-carotene into the PQ-treated cells resulted in an initial reduction in SOD activity (Fig. 1). At levels of $\beta$-carotene equal to $0 \cdot 1 \mu \mathrm{M}$, SOD activity was not significantly different from the non PQ-treated control value. However, following exposure of the cells to $\mathrm{PQ}$ and high concentrations of $\beta$-carotene $(1$ and $10 \mu \mathrm{M})$, SOD activity increased significantly $(P<0.032 ; P<0.001)$ relative to the control. A similar trend occurred when CAT activity was determined. $\beta$-Carotene at low levels $(0 \cdot 05,0 \cdot 1$ and $1 \cdot 0 \mu \mathrm{M})$ tended to return the CAT towards its control value. However, when the CEF were incubated with high levels of $\beta$-carotene $(10 \mu \mathrm{M})$, CAT activity increased again. As previously reported, PQ was found to inhibit GSH-Px activity (Stevens $e t$ al. 1988; Lawlor \& O'Brien, 1994). A level of $0.05 \mu \mathrm{M}$ - $\beta$-carotene protected GSH-Px activity but GSH-Px activity tended to be reduced relative to its control value at levels of $10 \mu \mathrm{M}-\beta$-carotene. Percentage LDH release, a measure of cell breakage, did not increase above $3.5 \%$ at low levels of $\beta$-carotene $(0-1.0 \mu \mathrm{M})$. However, percentage LDH release increased significantly $(P<0.005)$ in cells treated with $10 \mu \mathrm{M}-\beta$-carotene relative to cells not exposed to $\beta$-carotene.

With our second approach we tested the ability of cells grown in $\beta$-carotenesupplemented media to combat a PQ-induced oxidative challenge. The $\beta$-carotene-enriched CEF were incubated with $0.25 \mathrm{mM}-\mathrm{PQ}$ for $18 \mathrm{~h}$. The incorporation of PQ into the CEF resulted in an initial increase in SOD activity (Fig. 2). When cells grown in culture media enriched with $0 \cdot 1 \mu \mathrm{M}-\beta$-carotene were subjected to a PQ challenge, SOD activity was not significantly different from the control value. However, for cells grown in media supplemented with 5 and $10 \mu \mathrm{M}-\beta$-carotene, exposure to PQ resulted in the SOD activity increasing significantly $(P<0.001)$ relative to the control. A similar trend occurred when CAT activity was determined. $\beta$-Carotene at levels of $0 \cdot 1$ and $5 \mu \mathrm{m}$ in the media returned CAT to its control value. However, when the CEF were grown with high levels of $\beta$ carotene $(10 \mu \mathrm{M})$ in the culture medium, CAT activity increased significantly $(P<0 \cdot 009)$ 

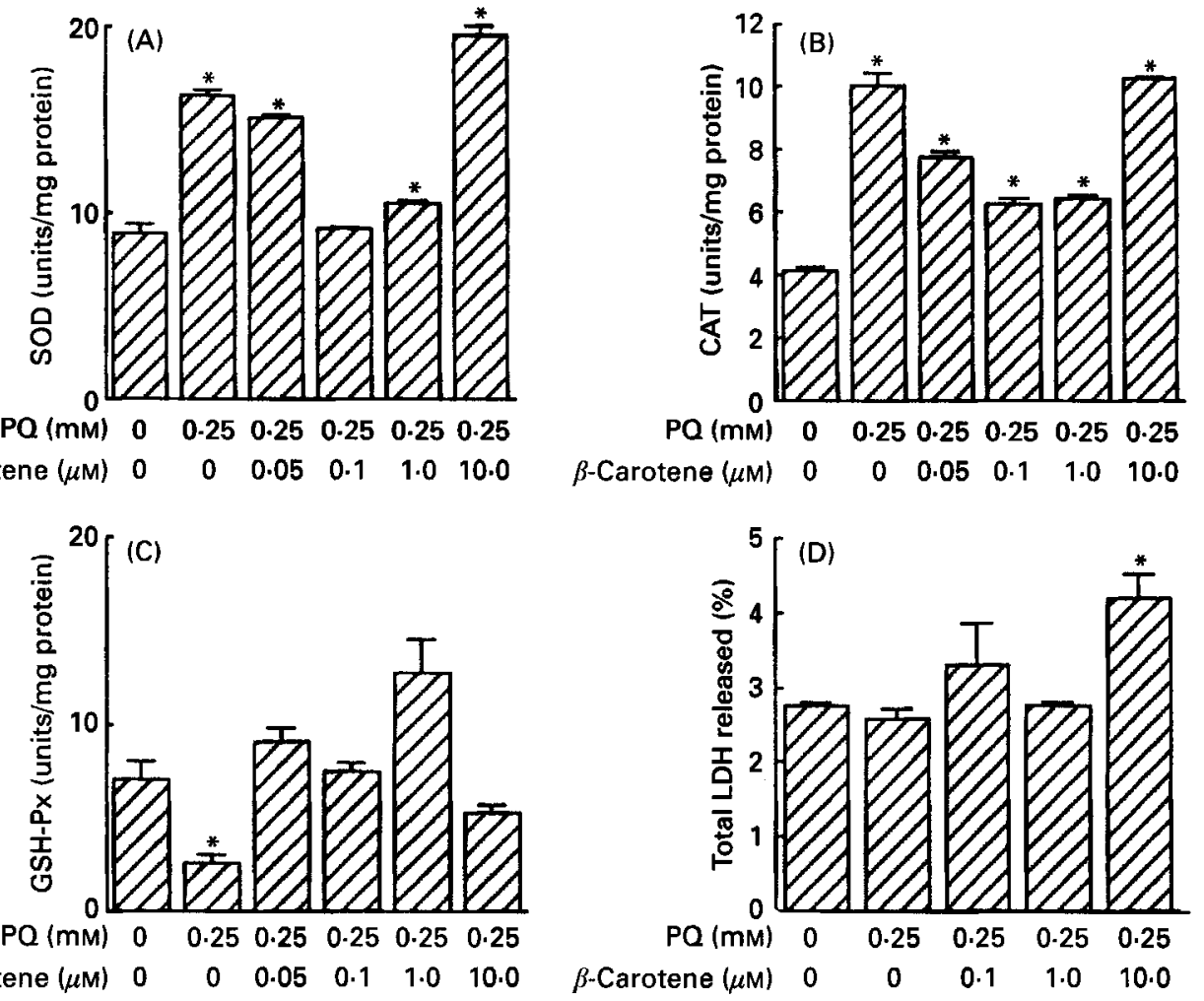

Fig. 1. Antioxidant enzyme activities in chicken embryo fibroblasts (CEF) incubated with or without paraquat (PQ, 0.25 mM) and 0-10 $\mu \mathrm{M}-\beta$-carotene for $18 \mathrm{~h}$. Values are means with their standard errors represented by vertical bars. (A), Total superoxide dismutase (SOD; $E C 1.15 .1 .1$ ) activity (units/mg protein), $n 3$ for all treatments. One unit is defined as the amount of SOD required to inhibit the maximum rate of cytochrome $\mathrm{C}$ reduction by $50 \%$. ${ }^{*}$ Mean values were significantly different from that for no $\mathrm{PQ}, P<0.05$. (B), Catalase (CAT; $E C$ 1.11.1.6) activity (units/mg protein), $n 5$ for all treatments. One unit is defined as $1 \mu \mathrm{mol} \mathrm{H}_{2} \mathrm{O}_{2}$ removed $/ \mathrm{min}$. * Mean values were significantly different from that for no PQ, $P<0.05$. (C), Glutathione peroxidase (GSH-Px; $E C$ 1.11.1.9) activity (units/mg protein), $n 3$ for all treatments. One unit is defined as the oxidation of $1 \mathrm{nmol}$ $\mathrm{NADPH} / \mathrm{min}$. *Mean values were significantly different from that for no $\mathrm{PQ}, P<0.05$. (D), Lactate dehydrogenase (LDH; $E C 1.1 .1$.27) release from PQ-treated and $\beta$-carotene-treated CEF. CEF were incubated with no PQ or $0.25 \mathrm{mM}-\mathrm{PQ}$ and the indicated concentrations of $\beta$-carotene for $18 \mathrm{~h}$. LDH activity in the medium was measured and expressed as a percentage of total LDH released from CEF treated with $100 \mathrm{~g} / 1$ Triton $\mathrm{X} ; n 4$ for all treatments. * Mean value was significantly different from that for no $\mathrm{PQ}, P<0.05$.

relative to the control. GSH-Px is inhibited by PQ (Stevens et al. 1988; Lawlor \& O'Brien, 1994). CEF grown in medium supplemented with all levels of $\beta$-carotene tested $(0 \cdot 1,5$ and $10 \mu \mathrm{M})$ protected GSH-Px activity. Percentage LDH release remained below $3 \%$ at all times.

\section{Effect of $\beta$-carotene alone on SOD, CAT and GSH-Px activities}

Results obtained in our model suggest that at the higher concentrations tested, $\beta$-carotene in the presence of PQ may exert pro-oxidant effects. We examined the effects of $\beta$-carotene without PQ treatment on the activities of the antioxidant enzymes in our CEF model system. CEF were incubated with $\beta$-carotene $(0.05-10 \mu \mathrm{M})$ in the medium for $18 \mathrm{~h}$ (Fig. 3). The incorporation of $\beta$-carotene into the CEF resulted in no significant change in SOD activity, but at the higher levels of $\beta$-carotene tested $(10 \mu \mathrm{M})$ the activity of the enzyme 

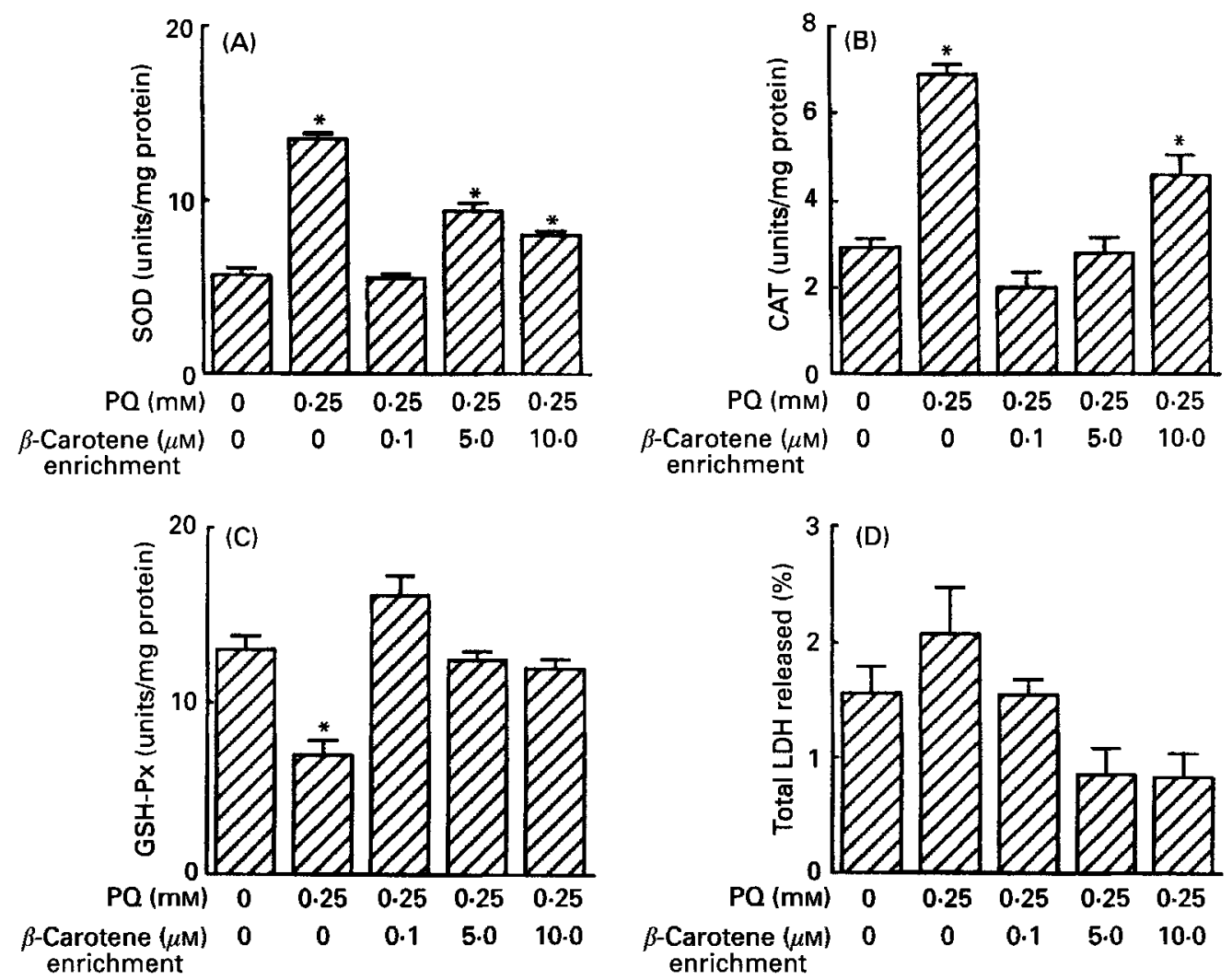

Fig. 2. Antioxidant enzyme activities in chicken embryo fibroblasts (CEF) grown in $\beta$-carotene-enriched media $(0-10 \mu \mathrm{M})$ and incubated with or without paraquat $(\mathrm{PQ} ; 0.25 \mathrm{~mm})$ for $18 \mathrm{~h}$. Values are means with their standard errors represented by vertical bars. (A), Total superoxide dismutase (SOD; EC 1.15.1.1) activity (units/mg protein), $n 5$ for all treatments. One unit is defined as the amount of SOD required to inhibit the maximum rate of cytochrome $\mathrm{C}$ reduction by $50 \%$. ${ }^{*}$ Mean values were significantly different from that for no $\mathrm{PQ}, P<0.05$. (B), Catalase (CAT; EC 1.11.1.6) activity (units/mg protein), $n 4$ for all treatments. One unit is defined as $1 \mu \mathrm{mol}$ $\mathrm{H}_{2} \mathrm{O}_{2}$ removed/min. ${ }^{*}$ Mean values were significantly different from that for no $P Q, P<0.05$. (C), Glutathione peroxidase (GSH-Px; EC 1.11,1.9) activity (units/mg protein), $n 4$ for all treatments. One unit is defined as the oxidation of $1 \mathrm{nmol} \mathrm{NADPH} / \mathrm{min}$. * Mean values were significantly different from that for no PQ, $P<0.05$. (D), Lactate dehydrogenase (LDH; $E C 1.1 .1 .27)$ release from PQ-treated CEF. CEF were treated with no PQ or $0.25 \mathrm{~mm}-\mathrm{PQ}$ for $18 \mathrm{~h}$. LDH activity in the medium was measured and expressed as a percentage of total LDH released from CEF treated with $100 \mathrm{~g} / 1$ Triton $\mathrm{X}, n 4$ for all treatments.

tended to increase compared with the control not exposed to $\beta$-carotene. A similar trend was seen when CAT activity was determined (Fig. 3). At levels of $\beta$-carotene ranging from 0.05 to $10 \mu \mathrm{M}$, CAT remained at its control value or lower. GSH-Px activity increased to its control value or higher in cells incubated with 0.1-10 $\mu \mathrm{M} \beta$-carotene. Percentage LDH release remained below $4 \cdot 0 \%$ at all times (results not shown).

\section{$\beta$-Carotene levels in CEF}

$\mathrm{CEF} \beta$-carotene content increased with increasing concentrations of $\beta$-carotene in the medium (Table 1) indicating that $\beta$-carotene was being taken up by the cells. However, at an incubation level of $10 \mu \mathrm{M}$ the $\beta$-carotene content of the cells was not significantly different from that of the cells treated with $1 \cdot 0 \mu \mathrm{M}-\beta$-carotene. 

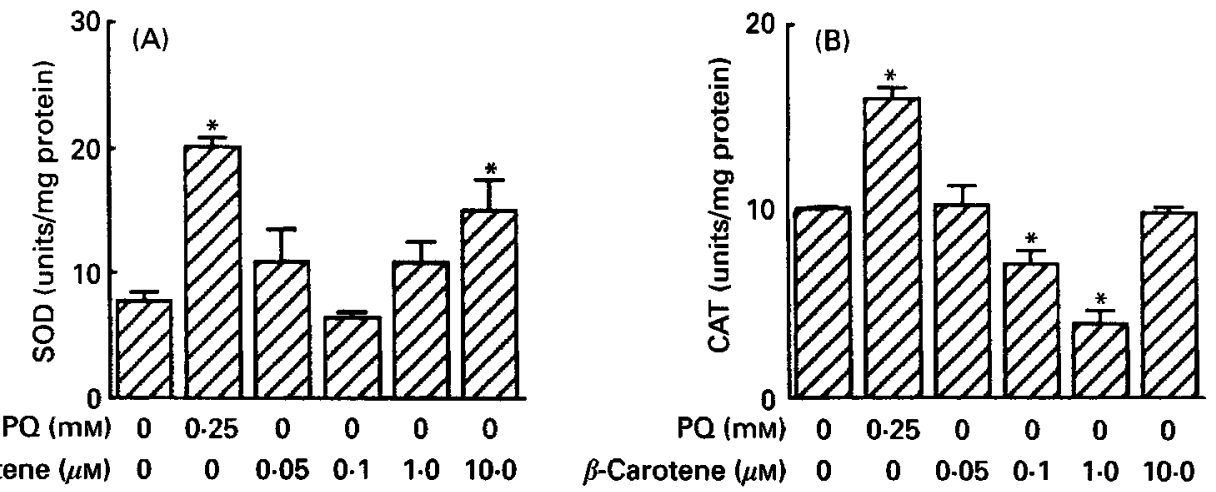

$\begin{array}{lllllll}\beta \text {-Carotene }(\mu \mathrm{M}) & 0 & 0 & 0.05 & 0.1 & 1.0 & 10.0\end{array}$

$\begin{array}{lllllll}\beta \text {-Carotene }(\mu \mathrm{M}) & 0 & 0 & 0.05 & 0.1 & 1.0 & 10.0\end{array}$

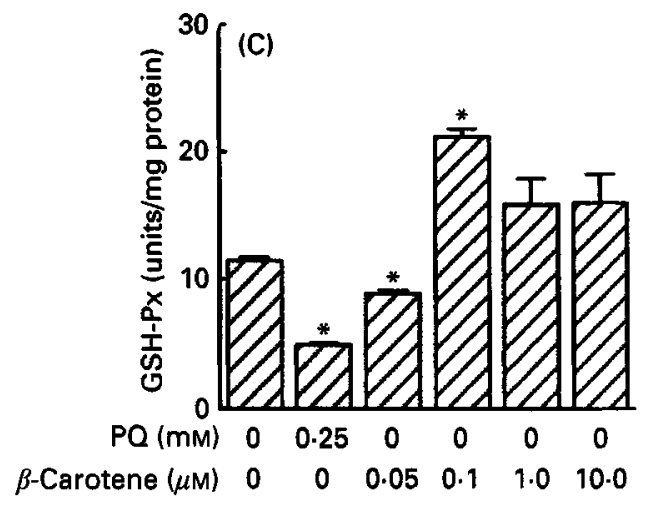

Fig. 3. Effect of $\beta$-carotene on the activities of antioxidant enzymes in chicken embryo fibroblasts (CEF), CEF were incubated with paraquat (PQ; $0.25 \mathrm{mM})$ or $\beta$-carotene $(0-10 \mu \mathrm{M})$ for $18 \mathrm{~h}$. Values are means with their standard errors represented by vertical bars. (A), Total superoxide dismutase (SOD; EC 1.15.1.1) activity (units/mg protein), $n 3$ for all treatments. One unit is defined as the amount of SOD required to inhibit the maximum rate of cytochrome $\mathrm{C}$ reduction by $50 \%$. ${ }^{*}$ Mean values were significantly different from that for no PQ, $P<0.05$. (B), Catalase (CAT; $E C 1.11 .1 .6$ ) activity (units/mg protein), $n 4$ for all treatments. One unit is defined as $1 \mu \mathrm{mol} \mathrm{H}_{2} \mathrm{O}_{2}$ removed/min. ${ }^{*}$ Mean values were significantly different from that for no $\mathrm{PQ}, P<0.05$. (C), Glutathione peroxidase (GSH-Px; $E C 1.11 .1 .9$ ) activity (units/mg protein), $n 3$ for all treatments. One unit is defined as the oxidation of $1 \mathrm{nmol} \mathrm{NADPH} / \mathrm{min}$. * Mean values were significantly different from that for no $\mathrm{PQ}, P<0.05$.

Table 1. $\beta$-Carotene content of chicken embryo fibroblasts $(C E F)$ treated with paraquat $(P Q)$ and $\beta$-carotene*

(Mean values with their standard errors for two determinations)

\begin{tabular}{lcc}
\hline \hline & \multicolumn{2}{c}{$\beta$-Carotene $(\mu \mathrm{g} / \mathrm{mg}$ protein $)$} \\
\cline { 2 - 3 } Treatment & \multicolumn{1}{c}{ Mean } \\
\hline Control $\dagger$ & 2.00 & 0.02 \\
PQ $(0.25 \mathrm{mM})$ & 0.86 & 0.03 \\
PQ $+\beta$-carotene $(0.1 \mu \mathrm{M})$ & 8.86 & 0.12 \\
PQ $+\beta$-carotene $(1.0 \mu \mathrm{M})$ & 23.51 & 0.05 \\
$\mathrm{PQ}+\beta$-carotene $(10.0 \mu \mathrm{M})$ & 23.33 & 0.03 \\
\hline
\end{tabular}

* CEF were incubated with $0.25 \mathrm{mM}-\mathrm{PQ}$ and the indicated concentrations of $\beta$-carotene for $18 \mathrm{~h}$. $\beta$-Carotene content of the CEF was then determined by HPLC analysis.

$\dagger$ Control cells containing no PQ or $\beta$-carotene. 


\section{DISCUSSION}

$P Q$, a toxin that increases intracellular oxidant formation, has been used to investigate the effects of oxidative stress on the antioxidant enzymes in CEF. A previous study demonstrated that $P Q$ does not affect the three antioxidant enzyme activities in a consistent manner: it induces SOD and CAT and inactivates GSH-Px (Lawlor \& O'Brien, 1994). Induction of SOD activity by PQ has also been reported in Chinese hamster ovary cells (Nicotera et al. 1985), human gingival fibroblasts (Stevens et al. 1988) and PQ-resistant HeLa (human cervix carcinoma) cells (Krall et al. 1991). As PQ generates the superoxide radical $\mathrm{O}_{2}^{-}$(Bus et al. 1974), either $\mathrm{O}_{2}^{-}$or a reaction product involving $\mathrm{O}_{2}^{-}$acts as an inducer of SOD activity.

In CEF, both SOD and CAT are induced at PQ levels of $0.25 \mathrm{~mm}$. In contrast, GSH-Px activity is decreased at this concentration of PQ. This is interesting as both CT and GSHPx metabolize $\mathrm{H}_{2} \mathrm{O}_{2}$ yet both respond differently to PQ treatment. CAT is inhibited by $\mathrm{O}_{2}^{-}$ in isolated enzyme systems (Kono \& Fridovich, 1982) but not in cell cultures. Stevens et al. (1988) found that CAT activity increased at $1.0 \mathrm{~mm}-\mathrm{PQ}$ and above in human gingival fibroblasts. CAT activity also increased in PQ-resistant HeLa cells on exposure to $90 \mu \mathrm{M}-$ PQ (Krall et al. 1991). It is thought that CAT is protected from $\mathrm{O}_{2}^{-}$by its location within the peroxisomes in cells. GSH-Px is located in the cytoplasm and therefore is not protected against $\mathrm{O}_{2}{ }^{-}$-induced inhibition (Blum \& Fridovich, 1985). We have previously shown that $\alpha$-tocopherol is capable of acting as an antioxidant in CEF treated with PQ (Lawlor \& O'Brien, 1994). In the present paper the ability of $\beta$-carotene to function as an antioxidant was examined in our model system.

PQ metabolism leads to the generation of a wide variety of free radicals and reactive $\mathrm{O}$ metabolites, notably the superoxide and hydroxyl radicals, $\mathrm{H}_{2} \mathrm{O}_{2}$ and singlet $\mathrm{O}$ (Vale \& Meredith, 1981). Further damage to polyunsaturated fatty acids may also lead to the production of peroxyl radicals. The antioxidant properties of carotenoids have been attributed to their ability to quench electronically excited molecules, e.g. singlet $O$, and also their ability to trap peroxyl and alkoxyl radicals (Packer et al. 1981).

Incorporation of $\beta$-carotene (0.1 $\mu \mathrm{M})$ into the PQ-treated CEF, either by incubating the cells with $\beta$-carotene for $18 \mathrm{~h}$ (Fig. 1) or by growing the cells in $\beta$-carotene-enriched media (Fig. 2), resulted in a decrease in both SOD and CAT activities, and GSH-Px activity was returned to its control value. However, at the higher concentration tested $(10 \mu \mathrm{M}) \beta$ carotene appeared to be acting as a pro-oxidant in both our experimental procedures. SOD and CAT activities increased significantly above control values and GSH-Px activity was lower than controls in the presence of $10 \mu \mathrm{M}$ - $\beta$-carotene (Figs. 1 and 2). Our findings are in agreement with studies by Burton (1989) who concluded that, due to its structure, $\beta$ carotene may act as an antioxidant at low concentrations/low $O$ pressures and as a prooxidant at high concentrations/high $O$ pressures. $\beta$-Carotene is an unusual type of lipidsoluble chain-breaking antioxidant. Conventional chain-breaking antioxidants such as $\alpha$ tocopherol trap radicals by donating a $\mathrm{H}$ atom. However, $\beta$-carotene exerts an antioxidant activity by a mechanism in which the chain-propagating peroxyl radical is trapped by addition to the conjugated polyene system of $\beta$-carotene rather than by hydrogen donation. The resulting $C$-centred radical is resonance-stabilized, leading to chain termination (Burton, 1989; Terao, 1989; Palozza \& Krinsky, 1992). At the atmospheric O concentration of our system we propose that $\beta$-carotene at low concentrations $(0 \cdot 1 \mu \mathrm{M})$ reacts with free radicals leading to the formation of a resonance-stabilized $\mathrm{C}$-centred radical ( $\beta$-car) causing a subsequent decrease in SOD and CAT activities. In the presence of high concentrations of $\beta$-carotene $(10 \mu \mathrm{M})$ and atmospheric $O$ concentrations a new chaincarrying $\beta$-carotene peroxyl radical $\left(\beta\right.$-car-OO $\left.{ }^{*}\right)$ may be formed. The high level of $\beta$ - 
carotene was seen to be toxic to the CEF as indicated by an increase in percentage LDH released (Fig. 1). The cell concentration of $\beta$-carotene was measured by HPLC. Increased uptake occurred when $\beta$-carotene increased in the medium (Table 1). However, no difference in $\beta$-carotene concentration was observed in cells incubated with 1.0 or $10 \mu \mathrm{M}$ $\beta$-carotene even though antioxidant enzyme effects were different at these two levels. At the $10 \mu \mathrm{M}$ incubation level, $\beta$-carotene may have been converted to its chain-carrying peroxyl radical form and was not detected at $450 \mathrm{~nm}$, the normal wavelength for $\beta$-carotene detection.

The effect of $\beta$-carotene on the antioxidant enzyme activity in CEF was examined without the presence of PQ. Incorporation of $\beta$-carotene into CEF resulted in a decrease in SOD and CAT activities and an increase in GSH-Px activity at low concentrations $(0 \cdot 05-0 \cdot 1 \mu \mathrm{M})$. On incubation with $10 \mu \mathrm{M}-\beta$-carotene, SOD and CAT activities increased and GSH-Px activity decreased relative to the control but not significantly. Therefore, in our model, at the high concentrations of $\beta$-carotene tested and without the confounding influences of $P Q$, trends in antioxidant enzyme activities are observed which support our suggestion that $\beta$-carotene may exhibit pro-oxidant properties.

$\beta$-Carotene was effective in our system as an antioxidant at concentrations of $0 \cdot 1 \mu \mathrm{M}$ under normal $O$ concentrations. Studies by Burton \& Ingold (1984) and Burton (1989) indicate that $\beta$-carotene is most effective as an antioxidant at low $\mathrm{O}$ tensions. To the best of our knowledge, studies on the antioxidant properties of $\beta$-carotene in a cell culture system at low $O$ tensions more representative of normal physiological conditions have not been reported. Future work in our model will address this issue. Results of these studies would give an indication of how effective an antioxidant $\beta$-carotene is in cell culture under physiological conditions of $\mathrm{O}$ exposure.

\section{REFERENCES}

Baudhuin, P., Beaufay, H., Rahman-Li, Y., Sellinger, O. Z., Wattiaux, R., Jacques, P. \& deDuve, C. (1964). Tissue fractionation studies. Intracellular distribution of monoamine oxidase, aspartate aminotransferase, Damino acid oxidase and catalase in rat liver tissue. Biochemical Journal 92, 179-184.

Blum, J. \& Fridovich, I. (1985). Inactivation of glutathione peroxidase by the superoxide radical. Archives of Biochemistry and Biophysics 240, 500-508.

Bradford, M. M. (1976). A rapid and sensitive method for the quantitation of microgram quantities of protein utilizing the principle of protein-dye binding. Analytical Biochemistry 72, 248-254.

Burton, G. W. (1989). Antioxidant action of carotenoids. Journal of Nutrition 119, 109-111.

Burton, G. W. \& Ingold, K. U. (1984). $\beta$-Carotene: an unusual type of lipid antioxidant. Science 224, $569-573$.

Bus, J. S., Auat, S. D. \& Gibson, J. E. (1974). Superoxide and singlet oxygen-catalyzed lipid peroxidation as a possible mechanism for paraquat (methyl viologen) toxicity. Biochemical and Biophysical Research Communications 58, 749-755.

Buttriss, J. L. \& Diplock, A. T. (1984). High-performance liquid chromatography methods for vitamin $\mathrm{E}$ in tissues. Methods in Enzymology 105, 131-138.

Di Mascio, P., Murphy, M. E. \& Sies, H. (1991). Antioxidant defense systems: the role of carotenoids, tocopherols, and thiols. American Journal of Clinical Nutrition 53, 194S-200S.

Guenzler, W. A., Kremers, H. \& Flohe, L. (1974). An improved coupled test procedure for glutathione peroxidase in blood. Zeitschrift fuer Klinische Biochemie und Klinische Chemie 12, 444448.

Harats, D., Dabach, Y., Hollander, G., Ben-Naim, M., Schwartz, R., Berry, E. M., Stein, O. \& Stein, Y. (1991). Fish oil ingestion in smokers and nonsmokers enhances peroxidation of plasma lipoproteins. Atherosclerosis $\mathbf{9 0}$, 127-139.

Jialal, I., Norkus, E. P., Cristol, L. \& Grundy, S. M. (1991). $\beta$-Carotene inhibits the oxidative modification of lowdensity lipoproteins. Biochimica et Biophysica Acta 1086, 134-138.

Kono, Y. \& Fridovich, I. (1982). Superoxide radical inhibits catalase. Journal of Biological Chemistry 257, 5751-5754.

Krall, J., Speranza, M. J. \& Lynch, R. E. (1991). Paraquat-resistant HeLa cells: increased cellular content of glutathione peroxidase. Archives of Biochemistry and Biophysics 286, 311-315.

Krinsky, N. I. (1989). Carotenoids and cancer in animal models. Journal of Nutrition 119, 123-126.

Krinsky, N. I. \& Deneke, S. M. (1982). Interaction of oxygen and oxy-radicals with carotenoids. Journal of the National Cancer Institute 69, 205-210. 
Kwei, G. Y. \& Bjeldanes, L. F. (1990). Stimulation of binding of benzo[a]pyrene metabolites to DNA by dietinduced peroxidative stress. Food and Chemical Toxicology 29, 491-495.

Lawlor, S. M. \& O'Brien, N. M. (1994). Development of an in vitro cell culture model to investigate the induction and quantification of oxidative stress and its inhibition by $\alpha$-tocopherol. Toxicology In Vitro 8, 67-73.

McCord, J. M. \& Fridovich, I. (1969). Superoxide dismutase. An enzymic function for erythrocuprein (hemocuprein). Journal of Biological Chemistry 244, 6049-6055.

Mathews-Roth, M. M. (1985). Carotenoids and cancer prevention-experimental and epidemiological studies. Pure and Applied Chemistry 57, 717-722.

National Academy of Sciences (1989). Diet and Health: Implications for Reducing Chronic Disease Risk. Washington, DC: National Academy of Sciences.

Nicotera, T. M., Block, A. W., Gibas, Z. \& Sandberg, A. A. (1985). Induction of superoxide dismutase, chromosomal aberrations and sister-chromatid exchanges by paraquat in Chinese hamster fibroblasts. Mutation Research 151, 263-268.

Packer, J. E., Mahood, J. S., Mora-Arellano, V. O., Slater, T. F., Willson, R. L. \& Wolfenden, B. S. (1981). Free radicals and singlet oxygen scavengers: reaction of a peroxy-radical with $\beta$-carotene, diphenyl furan and $1,4-$ diazobicyclo(2,2,2)-octane. Biochemical and Biophysical Research Communications 98, 901-906.

Palozza, P. \& Krinsky, N. I. (1992). $\beta$-Carotene and $\alpha$-tocopherol are synergistic antioxidants. Archives of Biochemistry and Biophysics 297, 184-187.

Palozza, P., Moualla, S. \& Krinsky, N. I. (1992). Effects of $\beta$-carotene and $\alpha$-tocopherol on radical-initiated peroxidation of microsomes. Free Radicals in Biology and Medicine 13, 127-136.

Peto, R., Doll, R. J., Buckley, J. D. \& Sporn, M. B. (1981). Can dietary $\beta$-carotene materially reduce human cancer rates? Nature 290, 201-208.

Snedecor, G. W. (1964). Sampling from a normally distributed population. In Statistical Methods, p. 45 [G. W. Snedecor and W. G. Cochran, editors]. Ames: Iowa State University Press.

Stevens, T. M., Boswell G. A. Jr, Adler, R., Ackerman, N. R. \& Kerr, J. S. (1988). Induction of antioxidant enzyme activities by a phenylurea derivative, EDU. Toxicology and Applied Pharmacology 96, 33-42.

Terao, J. (1989). Antioxidant activity of $\beta$-carotene-related carotenoids in solution. Lipids 24, 659-661.

Thurnham, D. I., Smith, E. \& Flora, P. S. (1988). Concurrent liquid chromatographic assay of retinol, $\alpha$ tocopherol, $\beta$-carotene, $\alpha$-carotene, lycopene and $\beta$-cryptoxanthin in plasma, with tocopherol acetate as internal standard. Clinical Chemistry 34, 377-381.

Vale, J. A. \& Meredith, T. J. (1981). Paraquat poisoning. In Poisoning, Diagnosis and Treatment, pp. 135-141 [J. A. Vale and T. J. Meredith, editors]. London: Update Books.

Vassault, A. (1983). Lactate dehydrogenase. In Methods of Enzymatic Analysis, pp. 118--126 [H. U. Bergmeyer, editor]. Weinheim, FRG: Verlag Chemie.

Ziegler, R. G. (1991). Vegetables, fruits, and carotenoids and the risk of cancer. American Journal of Clinical Nutrition 53, 251S-259S. 